\title{
Seismic vulnerability of a slope in central Italy
}

\author{
A. Ferraro, S. Grasso \& M. Maugeri \\ Department of Civil and Environmental Engineering, Italy
}

\begin{abstract}
This study has regarded the evaluation of site effects for seismic vulnerability in correspondence of a site in San Giuliano di Puglia (Italy), located in the Molise Region in Southern Italy, which is prone to high seismic risk. On October 31, 2002, a $\mathrm{M}_{\mathrm{L}}=5.4$ earthquake struck the Molise region in Southern Italy. The strongly non-uniform damage distribution observed in the town of San Giuliano di Puglia suggested that site amplification significantly affected the seismic response of the area. Accelerograms obtained from the recording of the aftershocks of the earthquake of October 31, 2002 have been used to evaluate the ground response analysis at the surface. Finally the 1-D computer code EERA was also used to model the equivalent-linear earthquake site response analyses of layered soil deposits. The detail with which the hill has been studied has allowed the construction of a detailed 2-D model of its structure. The difference between the computed ground motion for different Vs profiles has been explored using QUAD4M and QUAKE/W 2-D codes. It has also been possible to compare the results from different 1-D models used, reflecting current approaches to the determination of site response.
\end{abstract}

Keywords: seismic response, dilatometer, shear waves velocity, 2-D model.

\section{Introduction}

Depending on the modelling of geotechnical subsoil, site effects have been estimated in the area of San Giuliano di Puglia (Italy). A first crucial phase of the study was the characterization of the site. Detailed aspects of geological investigations, geotechnical characterisation and seismic action have been developed in the municipality of San Giuliano di Puglia, which allowed the determination of the physic-mechanical and kinematic investigation of land, used in numerical calculations. 
Synthetic seismograms obtained by Peter Klin (INOGS - Italy) have been used, calculated by the Fourier pseudo-spectral convolving the response of the local 3-D model of the S. Giuliano di Puglia site; in addition the synthetic seismograms calculated for a model of matching source at $\mathrm{M}=5.8,31$ October 2002 for a 1-D crustal have been also used. Thus using three different computational codes, Geodin, EERA and Quake/W, local one-dimensional seismic response analyses were performed. Finally the results obtained have been compared in terms of accelerations at the surface, elastic response spectra and amplification factors.

This work is framed in the project of the National Institute of Geophysics and Volcanology (INGV) of the Department of Civil Defence of Italy (DPC) which is called "Project S3 - shaking scenarios in areas of priority interest and /or strategic" [1].

The S3 Project had the overall objective of the calculation shaking scenarios in some areas of Italy in case of occurrence of the maximum credible earthquake (Maximum Credible Earthquake). Task 3 of the S3 project was to generate "shaking scenarios at the bedrock and to the site in some municipalities most affected by seismic sequence started on 31 October 2002". For these municipalities there is a considerable body of data on the distribution of damage on the geotechnical characterization of the subsoil and on the vulnerability of buildings (particularly in the municipality of San Giuliano di Puglia), but no records of the main shock in the epicentral area. The study that follows focuses on Local Seismic Response (RSL) of the town of San Giuliano di Puglia [2].

\section{Historical seismicity of the Molise Region}

The historical reconstructions showed that the Molise Region is a seismically very active zone. Almost all the earthquakes that have affected the Molise have an epicentre in the plains in front of the Matese massif and neighbouring areas in Campobasso. Among the highly destructive earthquakes we should mention three. The first, in 1456, is one of the most documented and is known as "the earthquake in Naples. This earthquake with XI MCS destroyed the cities of Isernia and Campobasso. The second, in 1688, with XI MCS interested a wide area of Sannio causing heavy damage. The third, in 1805, is important for the historical seismology of Molise as was the epicentre of the Maltese eastern faults, near the Agro Baranello, with damage caused in an area of 600 square kilometres, completely destroying the town of Boiano and causing more than 6000 victims (Figure 1).

The strong historical earthquakes such as those mentioned above suggest that the southern sector of Appennino is one of the areas with higher seismic risk. This area is also characterized by sequences of low seismic energy that may go on for several months. Among the more recent sequences it is possible to include those of 1986 and of 1997. The first covers the area located to north-east from Isernia with a magnitude $M=4$. The second was concerned with the area bordering the region of Campania, with a magnitude $\mathrm{M}=4.1$, and intervals of intense seismic activity with periods of relative quiescence, lasted about a year. 


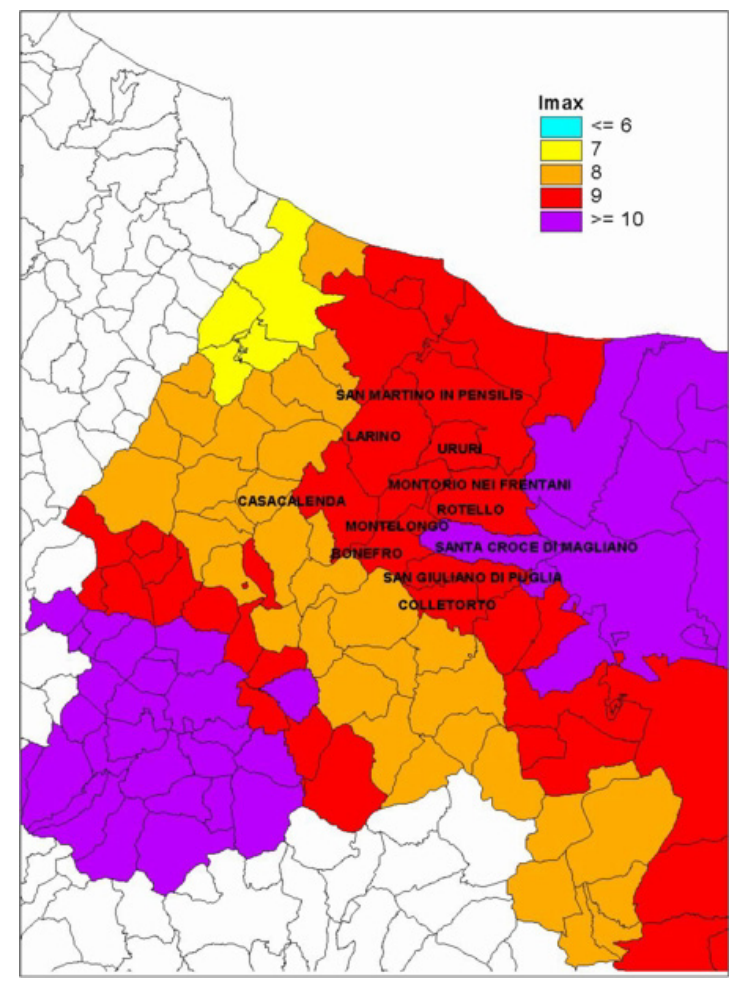

Figure 1: Maximum intensity observed in the last millennium (from the website of INGV).

Currently, the seismicity of Molise is characterized by isolated low-energy, like that of March 2001, of magnitude $M=3.2$, which was the epicentre area between the municipalities of Miranda, Sessano and Isernia.

\section{The San Giuliano di Puglia earthquake of 31 October 2002}

The area affected by the earthquake of $31^{\text {st }}$ October 2002 (Figure 2) has not ever been affected by events comparable to those which affected areas of the Gargano promontory and the Molise Apennine. Indeed, in these areas, disastrous earthquakes (Io> IX MCS) have been recorded in the fifteenth century (1456, $1466)$, in the seventeenth $(1627,1646,1688,1694)$, in the eighteenth $(1702$, $1731,1732)$, in the nineteenth century $(1805,1851)$ and in the twentieth century $(1930,1962,1980)$. The effects produced by some of these earthquakes in the epicentral earthquake zone of 31 October 2002 seism have reached the threshold of damage [3].

On $31^{\text {st }}$ October 2002 at 11:32 a.m. local time, a strong earthquake $\left(\mathrm{M}_{\mathrm{L}}=5.4 \mathrm{Mw}=5.7\right)$ affected the central and southern areas of the country [4], with epicentre near the town of San Giuliano di Puglia in the Province of Campobasso, in a S-E zone compared to the capital, of about $20 \mathrm{Km}$. 


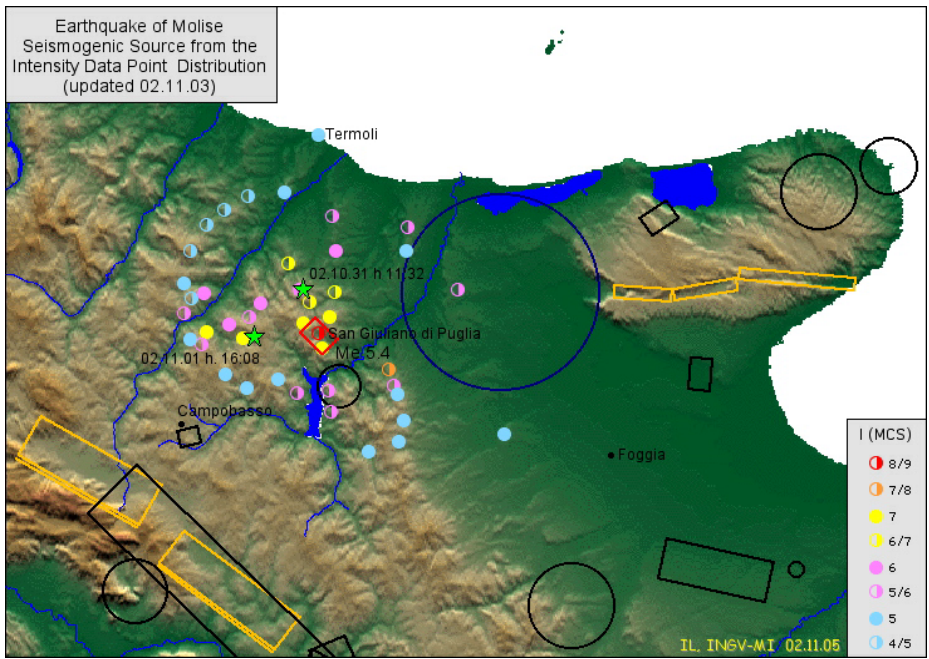

Figure 2: $\quad$ Parameters of the earthquake source from the data of intensity.

The main shock, as is often characteristic of the phenomenon, was also preceded in time by other events of minor magnitude. The maximum effects were found in a restricted area between Frentani and Sannio in the Provinces of Campobasso and Foggia.

In particular, in San Giuliano di Puglia, there have been partial collapses of masonry buildings in the central part of the country, some total collapses and a widespread serious damage. Infrastructure damage has been observed even in historical locations Bonefro, Casalnuovo Monterotaro, Castellino del Biferno, Colletorto, Ripabottoni, S. Croce di Magliano.

The event is followed by a seismic sequence that lasted several months, the strongest event of the sequence is recorded on 1 November $2002\left(\mathrm{M}_{\mathrm{L}}=5.3\right.$, Mw $=5.7$ ), (Lat. 41.69, Long. 14.83) creating new terror in the population and a worsening of the damage (Figure 3).

This seismic event, beyond the grief and sorrow caused by the victims, drew the attention of researchers engaged in the constant improvement of methods of analysis of vulnerability and viability of the buildings.

\section{Geological model and geotechnical characterization of soil}

The Municipality of San Giuliano di Puglia is built on a narrow ridge oriented in NNW-SSE direction, to the average of 450 meters above sea level [5].

The subsoil is characterized by the presence of two main units, which extend in depth to several hundred meters of the flysch Faeto, outcropping in the centre, and marly clays of Toppo Capuana, in the latest urban development [6]. The flysch of Faeto consists of an alternation of limestones, marly limestones, white marls and green clays, both surfaces of the ridge into the southern sector than in a northern mountain town. 


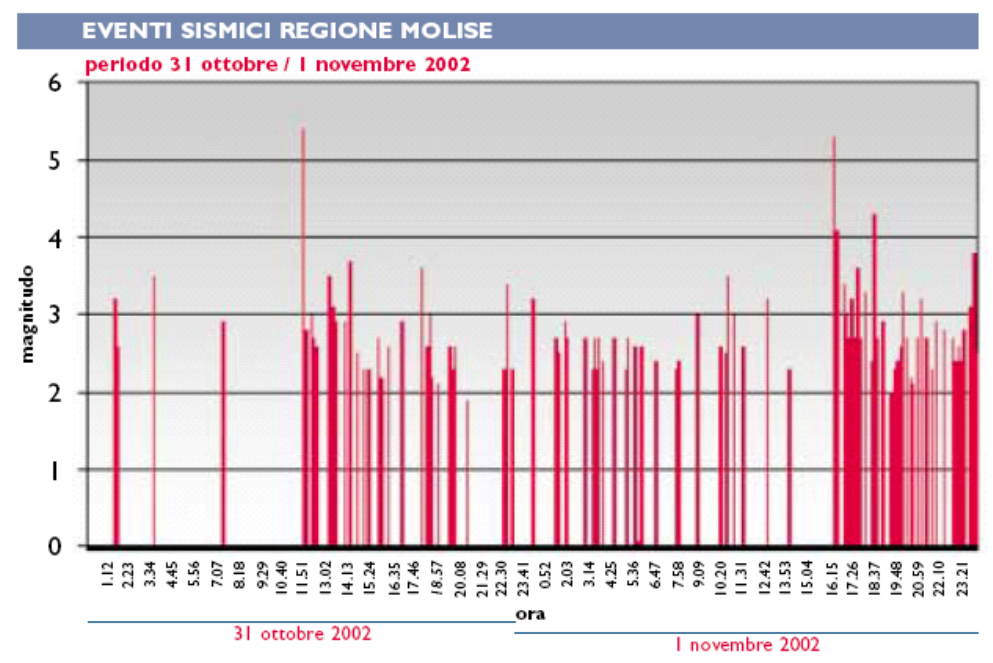

Figure 3: $\quad$ Seismic events from the period 31 October-1 November 2002.

The unit of Toppo Capuana consists primarily of gray blue marly clays and clayey marls. The deposition of marly clays is everywhere covered with a detritus, with variable thickness, consisting of heterogeneous materials. The in situ campaigns in the area under consideration are divided into four chronological groups (Figure 4):

1) before the seismic crisis with surveys of the Municipality of San Giuliano di Puglia (1992) and Molise Region (1996), localized predominantly in areas of potential expansion in the N-NW of the town;

2) immediately after the seismic crisis: (January-March 2003), aimed at microzonation [7] and FOR judicial investigations of the collapse of "F. Jovine School", with the main objective of characterizing a longitudinal section and a transverse the backbone of the town;

3) surveys for the reconstruction of the city centre (2004-2005) and carried out intensively in the area;

4) surveys conducted in July 2006 using the seismic dilatometer (SDMT) in the vicinity of the borings $\mathrm{S} 1, \mathrm{~S} 3$ and $\mathrm{S} 9$.

\section{D-H, CPT, DPT in situ tests}

It is well known that the physic-mechanical properties of most interest to the numerical modelling of the seismic local response [8] are:

- weight of the volume of soil and substrate $(\gamma=\rho g)$;

- seismic velocities $V_{S}$ and $V_{P}$ in the soil and substrate;

- laws of degradation parameters $G$ and $D$.

The first the results obtained from D-H, CPT and DPT tests have been analyzed.

The results obtained from Dynamic Penetration Test (DPT) and Cone Penetration Test (CPT), performed in the area investigated, were used to obtain 


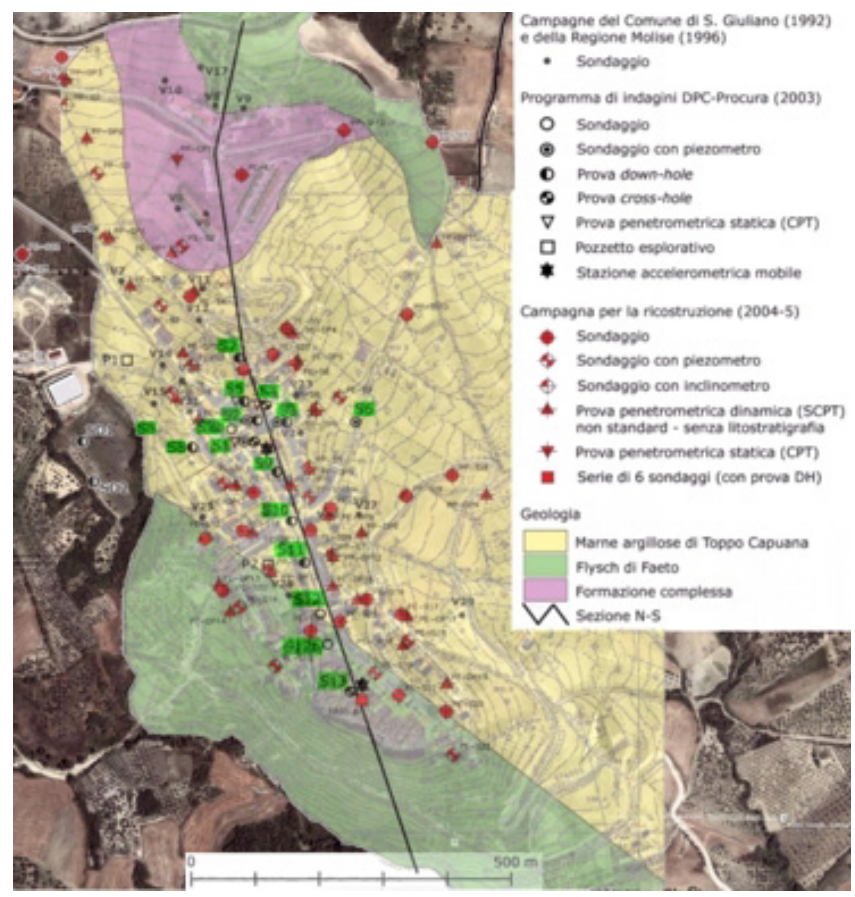

Figure 4: Locations of available geognostic surveys over the geological map.

through empirical correlations known in literature the values of shear waves velocity to the processing performed with the softwares 1-D codes Geodin and EERA.

For DPT tests were used the following correlations:

- Ohta and Goto [9]:

$$
V_{S}=54.33 \cdot\left(N_{S P T}\right)^{0.173} \cdot \alpha \cdot \beta \cdot\left(\frac{Z}{0.303}\right)^{0.193}
$$

where: $V_{S}$ shear waves velocity $(\mathrm{m} / \mathrm{s}) ; \mathrm{N}_{\mathrm{SPT}}$ blow-count SPT; $Z$ depth $(\mathrm{m}) ; \alpha$ age factor $($ Holocene $=1.000$, Pleistocene $=1.303) ; \beta$ geological factor $($ clays $=$ 1.000 , sands $=1.086)$.

- Yoshida and Motonori [10]:

$$
V_{S}=\beta \cdot\left(N_{S P T}\right)^{0.25} \cdot \sigma_{V_{0}}^{\prime 0.14}
$$

where: $V_{S}$ shear wave velocity $(\mathrm{m} / \mathrm{s}) ; \mathrm{N}_{\mathrm{SPT}}$ blow-count SPT; $\sigma^{\prime}{ }_{V 0}$ effective vertical stress; $\beta$ geological factor (any soil $=55$, fine sand $=49$ ).

For CPT tests was used the following correlation:

- Mayne and Rix [11]:

$$
G_{0}=\frac{406 \cdot q_{c}}{e^{1.13}}
$$




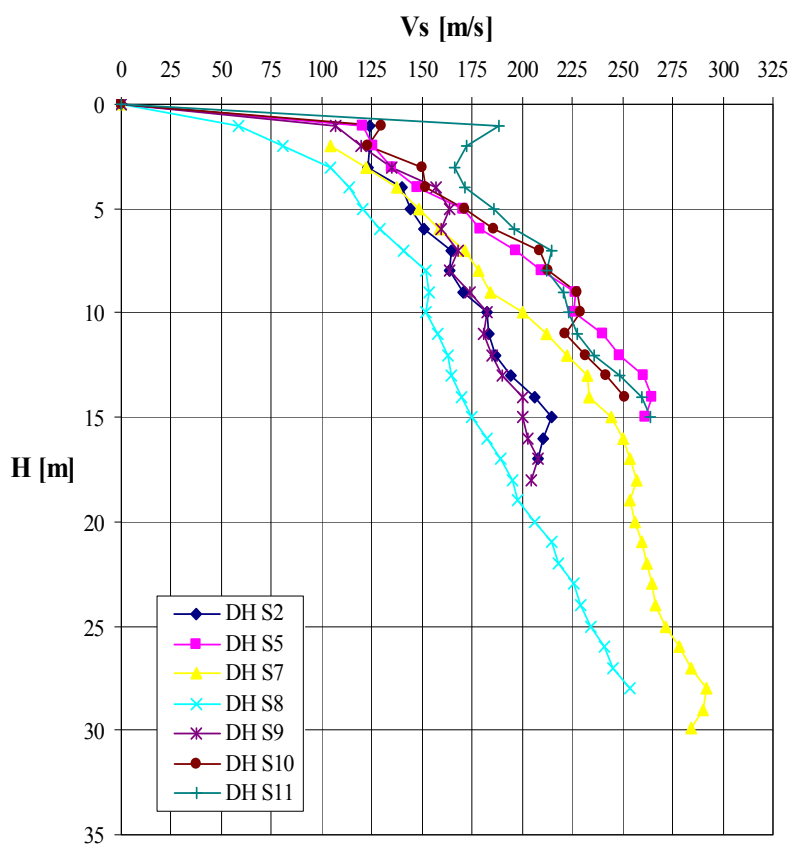

Figure 5: Trend of Vs profiles obtained from D-H tests at sites S2, S5, S7, S8, S9, S10, S11.

where: $G_{0}$ shear modulus $(\mathrm{kPa}) ; q_{C}$ tip resistance $(\mathrm{kPa}) ; e$ void ratio.

Figure 5 shows Vs profiles obtained from D-H tests, while Figure 6 shows Vs profiles obtained by empirical correlations based on CPT tests.

\section{Seismic dilatometer Marchetti test (SDMT)}

Near the school F. Jovine were carried out some tests with the seismic dilatometer (SDMT) [12]. The tests were performed by moving forward through the SDMT thrust applied by a penetrometer truck of 20 tons. Each test was conducted up to rejection, or until the pressure of 20 tons was no longer sufficient to advance the probe. Figure 7 shows the location of the three SDMT tests at San Giuliano di Puglia.

\section{Seismic response analysis of San Giuliano di Puglia}

Synthetic seismograms $\left(f_{\max }=8 \mathrm{~Hz}\right)$ for each site, calculated by Peter Klin (INOGS - Italy) with the Fourier pseudo-spectral method, have been utilised. Two codes, GEODIN [14] and EERA [15] have been used to evaluate the dynamic response of the soil in one-dimensional plane [13]. In this model, in 


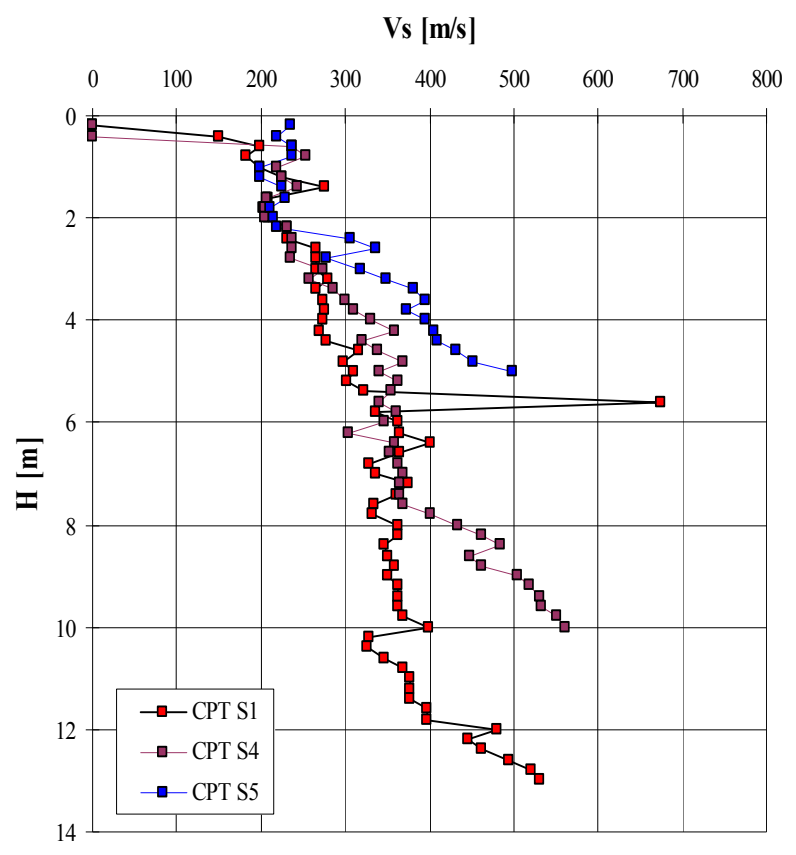

Figure 6: Trend of Vs profiles obtained by empirical correlations based on CPT tests at sites S1, S4, S5.

fact, different lithologic layers are arranged according to the soil model horizontal, parallel and infinitely extended. Later, the results obtained from analysis of response by these two codes, it was decided to deal with 1-D column on the same soil, with a code of finite element calculation, the Quake/W, which will then perform a 2-D analysis for San Giuliano di Puglia site.

\section{Results of numerical simulations}

Linear-equivalent analyses have been performed using the three codes Geodin, Eera and Quake/W. The tests were carried out taking into account the stratigraphic profiles and the input accelerograms described previously (Figure 8). The comparisons have been made in terms of response spectra and profiles of maximum acceleration. The results showed that codes for the calculation starting from the same input data, leading to comparable results between them. For example in Figures 9 and 10 are shown respectively the results for the borehole $\mathrm{S} 1$ in terms of maximum accelerations and response spectra, near the site where was built the school F. Jovine collapsed during the earthquake of 2002 . 


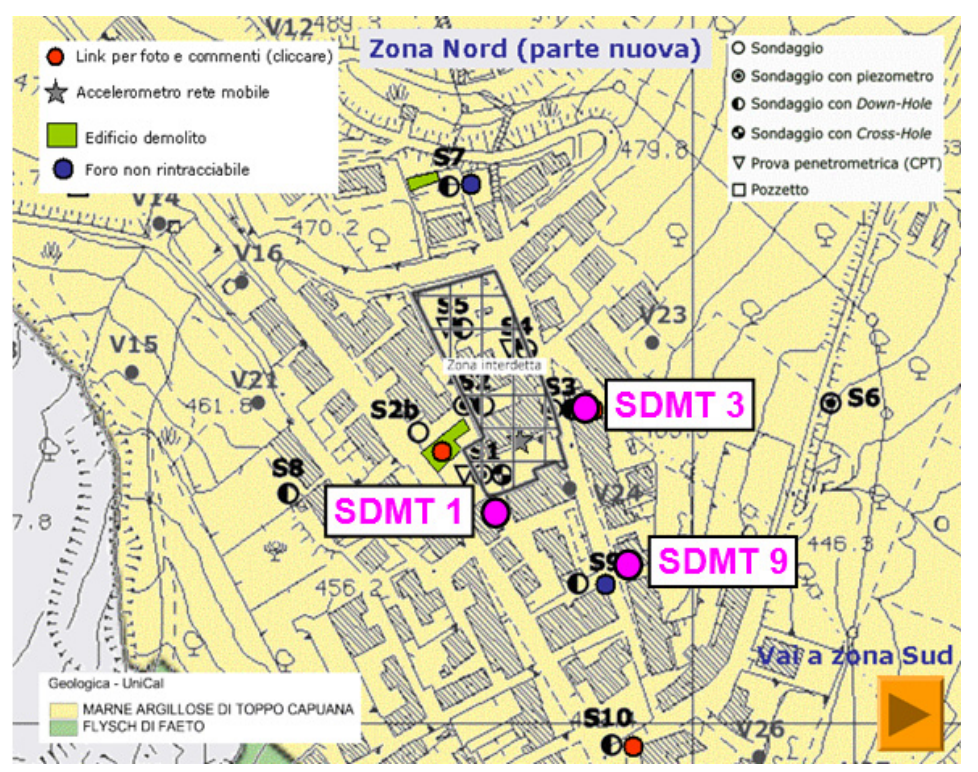

Figure 7: $\quad$ Location of SDMT tests.

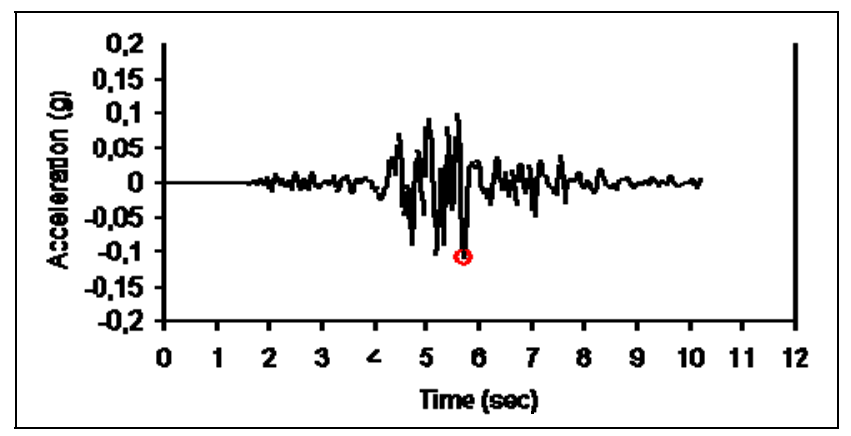

Figure 8: $\quad$ Input seismogram used for the test in S1 borehole.

\section{Conclusions}

The possibility of several in situ and laboratory tests made it possible to obtain a good characterization of materials through a careful interpretation of the tests; in addition particular attention was devoted to the tests with the new Seismic Dilatometer Marchetti Test (SDMT). It was also appreciated the usefulness of synthetic seismograms, for the purpose of the analysis of local seismic response and to work directly on the tracks of time acceleration, since it had no available records of the mainshock acceleration data. It was highlighted the importance of benchmarking results when using different computational codes because each code is able to reproduce some characteristics of seismic motion which depend on the numerical description of the source and on the means of propagation. 


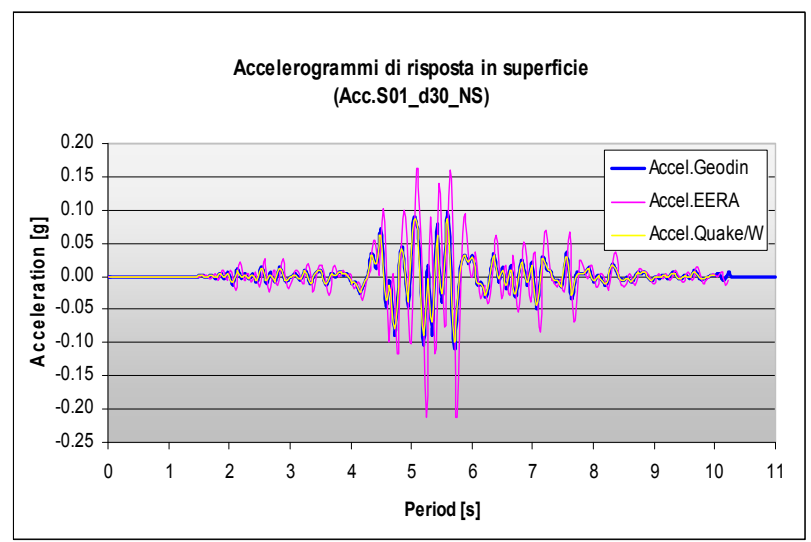

Figure 9: Comparison between surface accelerograms obtained using Geodin, Eera and Quake/W codes.

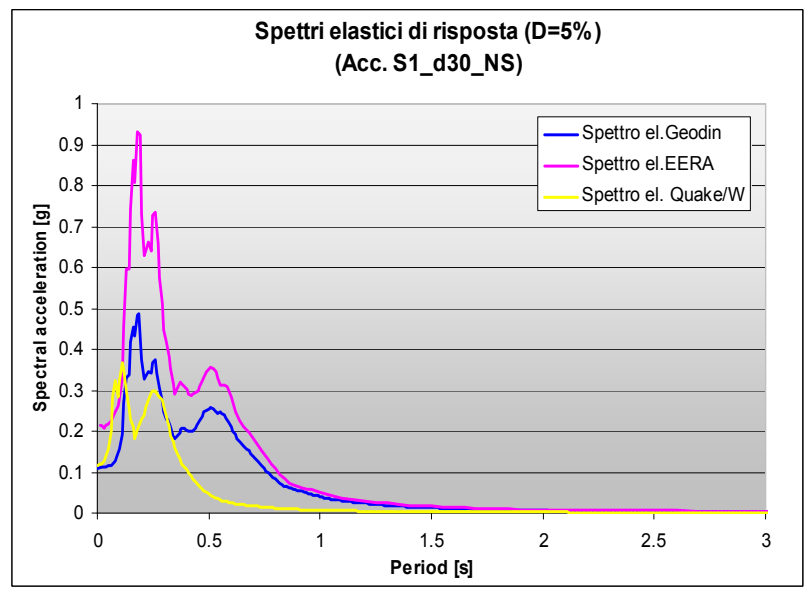

Figure 10: Comparison between response spectra obtained using Geodin, Eera and Quake/W codes.

\section{References}

[1] Mucciarelli, M., Pacor, F., 2007. Progetto S3 - Scenari di scuotimento in aree di interesse prioritario e/o strategico. Rapporto scientifico finale (1 giugno 2005-31 luglio 2007). Progetti sismologici di interesse per il DPC Rendicontazione conclusiva INGV.

[2] Puglia, R., Silvestri, F., 2007. Analisi di Risposta Sismica Locale del Centro Urbano di San Giuliano di Puglia (CB). Incontro Annuale dei Ricercatori di Geotecnica (IARG) 2007, Salerno, Italy. 
[3] Ferraro, A., 2007. Analisi della risposta sismica locale di San Giuliano di Puglia (CB), Tesi di Laurea in Ingegneria Civile, A.A. 2006-2007.

[4] Cubellis, E., Maturano, A., 2002. Il Terremoto del Molise del 31 October 2002 - Indagine macrosismica.

[5] Puglia, R., Lanzo, G., Pagliaroli, A., Sica, S., Silvestri, F., 2007. Ground motion amplification in San Giuliano di Puglia (Southern Italy) during the 2002 Molise earthquake. IV International Conference on Earthquake Geotechnical Engineering, Thessaloniki, Greece, paper no. 1611.

[6] Giaccio, B., Ciancia, S., Messina, P., Pizzi, A., Saroli, M., Sposato, A., Cittadini, A., Di Donato, V., Esposito, P., Galadini, F., 2004. Caratteristiche geologico-geomorfologiche ed effetti di sito a San Giuliano di Puglia (CB) e in altri abitati colpiti dalla sequenza sismica dell'ottobrenovembre 2002. Il Quaternario (Italian Journal of Quaternary Sciences), 17(1), Ed. Aiqua, pp. 83-99.

[7] Baranello, S., Bernabini, M., Dolce, M., Pappone, G., Rosskopf, C., Sanò, T., Cara, P.L., De Nardis, R., Di Pasquale, G., Goretti, A., Gorini, A., Lembo, P., Marcucci, S., Marsan, P., Martini, M.G., Naso, G., 2003. Rapporto finale sulla Microzonazione Sismica del centro abitato di San Giuliano di Puglia. Dipartimento di Protezione Civile, Roma.

[8] Lanzo, G., Silvestri, F., 1999. Risposta sismica locale: teorie ed esperienze, Argomenti di Ingegneria Geotecnica, Hevelius Edizioni, Benevento.

[9] Ohta, Y., Goto, N., 1978. Empirical Shear Wave Velocity Equations in Terms of Characteristic Soil Index. Earthquake Engineering and Structural Dynamics, Vol. 6.

[10] Yoshida, Y., Motonori, I., 1988. Empirical Formulas for SPT Blow-Counts for Gravelly Soils. Proceedings of ISOPT-1, Orlando, USA.

[11] Mayne, P.W., Rix, G.J., 1993. G $\max _{\max }-\mathrm{qc}$ Relationships for Clays", Geotechnical Testing Journal, Vol. 16, N. 1, pp. 54-60.

[12] Ferraro, A., Grasso, S., Maugeri, M., 2009. Site effects evaluation procedures for performance-based design. International Conference on Performance-Based Design in Earthquake Geotechnical Engineering from case history to practice. June 15-18, 2009 Tsukuba International Congress Centre JAPAN.

[13] Cavallaro, A., Ferraro, A., Grasso, S., Maugeri, M., 2008. Site Response Analysis of the Monte Po Hill in the City of Catania. MERCEA'08 - The 2008 Seismic Engineering International Conference commemorating the 1908 Messina and Reggio Calabria Earthquake. 08-11 July 2008. American Institute of Physics, Edited by A. Santini and N. Moraci.

[14] Frenna, S. M., Maugeri, M., 1995. GEODIN: a Computer Code for Seismic Soil Response. Proceeding of the. $9^{\text {th }}$ Italian Conference of Computational Mechanics, Catania, Italy, 20-22 June 1995, (in Italian). pp 145 - 148.

[15] Bardet, J. P., Ichii, K., Lin, C.H., 2000. EERA - A computer Program for Equivalent-linear Earthquake Site Response Analyses of Layered Soil Deposits. University of Southern California, Department of Civil Engineering. 